\title{
Delayed Mesh Infection: A Rare Complication of Laparoscopic Inguinal Hernia Repair (TEP-Totally Extra-Peritoneal Repair)
}

\section{Anand Kumar Yadav*, Vivek Bindal, Vinod Kumar Jangra, Zuber Khan, Shahnawaz Ahangar, Vikram Sharanappa, Mukund Khetan, Suviraj John, Sudhir Kalhan, Parveen Bhatia}

Institute of Minimal Access, Metabolic and Bariatric Surgery (iMAS), Sir Ganga Ram Hospital, New Delhi, India

Email: ^dranandyadav2005@gmail.com

How to cite this paper: Yadav, A.K., Bindal, V., Jangra, V.K., Khan, Z., Ahangar, S., Sharanappa, V., Khetan, M., John, S., Kalhan, S. and Bhatia, P. (2016) Delayed Mesh Infection: A Rare Complication of Laparoscopic Inguinal Hernia Repair (TEP_Totally Extra-Peritoneal Repair). Surgical Science, 7, 453-460.

http://dx.doi.org/10.4236/ss.2016.710061

Received: September 5, 2016

Accepted: October 7, 2016

Published: October 10, 2016

Copyright $\odot 2016$ by authors and Scientific Research Publishing Inc. This work is licensed under the Creative Commons Attribution International License (CC BY 4.0).

http://creativecommons.org/licenses/by/4.0/

\begin{abstract}
Hernias are amongst the oldest afflictions of mankind. The tension-free mesh repairs revolutionized and radically changed the whole concept of anatomical tissue repairs. The introduction of mesh, though beneficial, posed a new set of postoperative problems with the mesh infection being the most morbid one. Laparoscopic surgery has been able to reduce the incidence of mesh infection as opposed to the open hernia repairs. The infection occurs mostly early but rarely does it present several years after the surgery. Herein we report our case of delayed mesh infection developing 6 years postoperatively. This is our first such case in a series of more than 1000 laparoscopic hernia repairs over a period of 6 years (2010-2016). The patient needed an open exploration which revealed a large preperitoneal cavity containing $770 \mathrm{ml}$ of pus with a mesh floating in it. The mesh was removed and the thorough toileting of the wound was done.
\end{abstract}

\section{Keywords}

Laparoscopic Hernia Repair, Mesh Infection, Mesh Rejection, Pre-Peritoneal Cavity, Tacks, Erosion

\section{Introduction}

The original anatomical tissue repairs for hernia have an inherent problem of being under tension. The introduction of tension free repair by Lichtenstein served as a better alternative [1]. The majority of repairs today, open or laparoscopic, are performed with some sort of mesh tension-free repair. The complications usually occur in the imme- 
diate perioperative period like wound seroma, hematoma, urinary retention, bladder injury, and superficial wound infection. A number of problems have been seen to occur late after the surgery which includes post-herniorrhaphy neuralgia, testicular complications, mesh infection, recurrent hernia, and mesh migration and erosion. The incidence of mesh infection following laparoscopic repair has been reported to be $0.1 \%$ to $0.2 \%$ [1]-[3]. The mesh infection could be acute as well as delayed. This can present as a simple abdominal swelling or as pyrexia of unknown origin.

\section{Case}

A 65-year-old gentleman presented with complains of swelling in right lower abdomen for 25 days, associated with vague lower abdominal discomfort. The swelling had suddenly increased in size for the last 5 days along with the development of fever.

The patient had undergone laparoscopic total extra peritoneal repair of right inguinal hernia in 2010 using a $15 \times 15 \mathrm{~cm}$ polypropylene mesh. Post-operative period was uneventful. There was no recent history of abdominal trauma or any treatment including needle aspiration of swelling. Patient is a known diabetic for past 6 years controlled on oral hypoglycemic drugs.

On examination, he was febrile, with stable hemodynamic parameters. Per-abdominal examination revealed a diffuse bulge associated with tenderness in right lower abdomen. Per-rectal examination was unremarkable.

\section{Investigations}

Total leucocyte count was raised $(13,600) \& \mathrm{HbA1c}$ was 7.80 . The high frequency ultrasound examination, revealed a floating mesh in the pre-peritoneal cavity (Figure 1) and a $13 \times 13 \times 6.8 \mathrm{~cm},(772 \mathrm{cc})$ echogenic collection anterior to mesh in the right groin area suggestive of hematoma. Another anechoic collection with internal debris is seen on right of urinary bladder and is probably in continuation with hematoma (Figure 2 and Figure 3).

Contrast enhanced tomography was suggestive of collection with floating mesh inside.

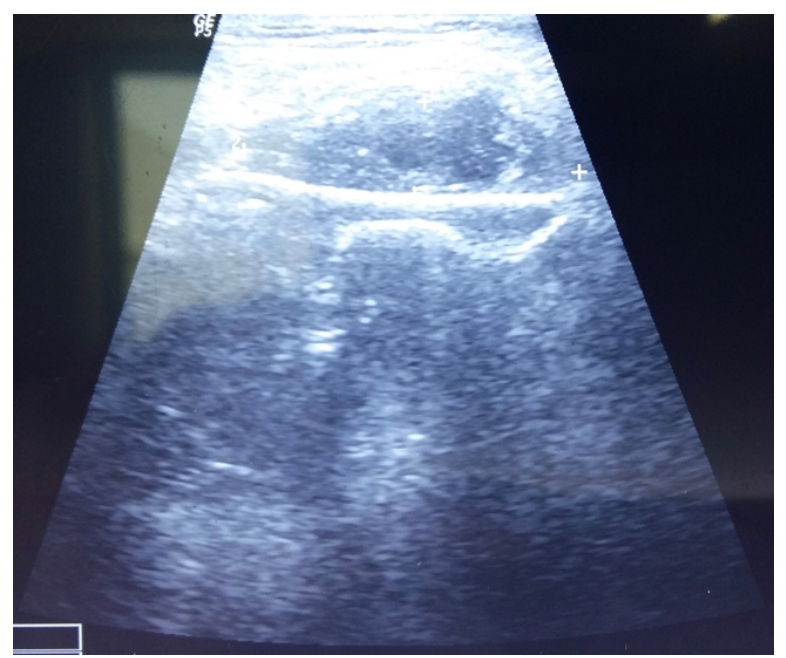

Figure 1. Ultrasound picture showing floating mesh in preperitoneal cavity. 


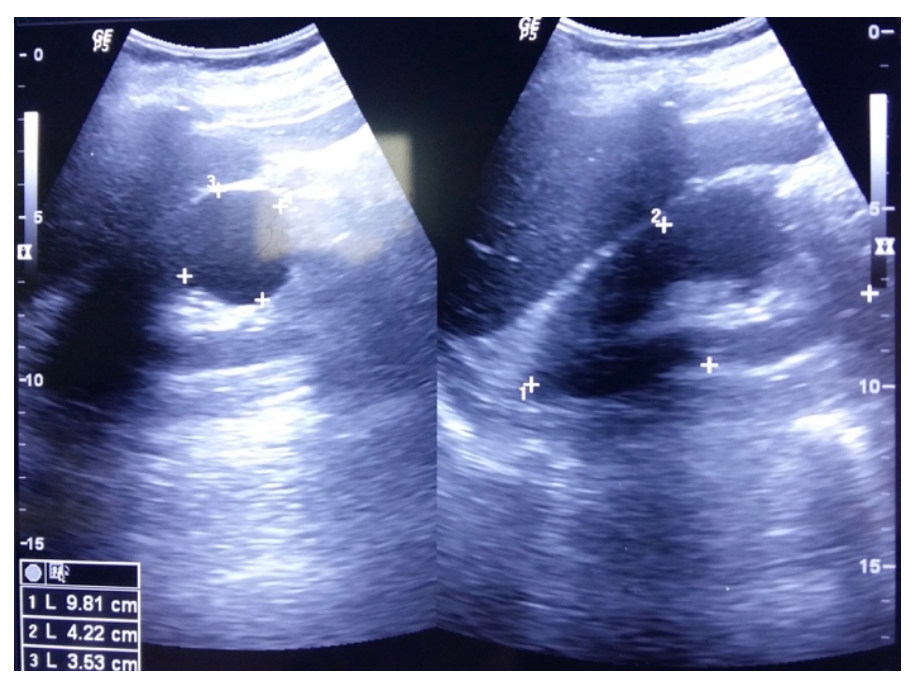

Figure 2. Ultrasound picture showing collection around mesh.

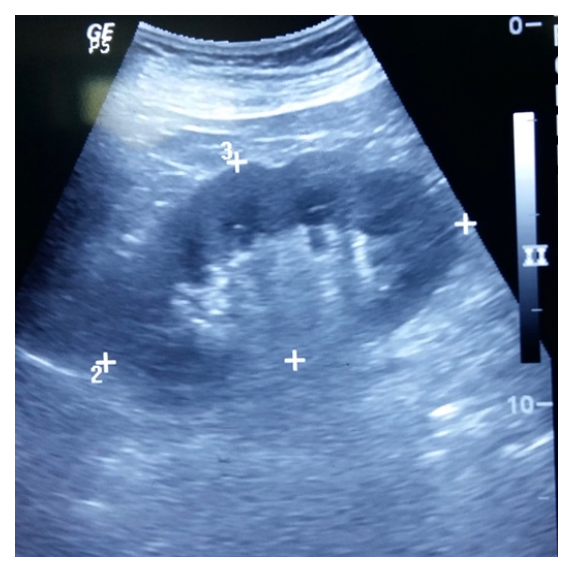

Figure 3. Ultrasound picture showing collection with internal debris.

\section{Differential Diagnosis}

The clinical examination and radiological findings were in favor of spontaneous rectus sheath hematoma as the most likely diagnosis. Primary appendicular pathology associated with collection, psoas abscess were the other differentials. Mesh related complication (infection), although rare, was also thought.

\section{Treatment}

The patient underwent an emergency exploration of right inguinal region. Per-operative finings revealed a large preperitoneal thick walled abscess cavity containing $500 \mathrm{ml}$ of pus (Figure 4) and a freely floating mesh (Figure 5). Spiral tacks were also recovered (Figure 6). There was no evidence of its extension into the peritoneal cavity (Figure 7). The mesh was removed followed by the lavage of cavity and closure over a suction drain (Figure 8). Postoperative recovery was uneventful and the patient was discharged subsequently. The pus culture reported E. coli sensitive to amikacin, aztreonam, cefepime, colistin, imipenem. 


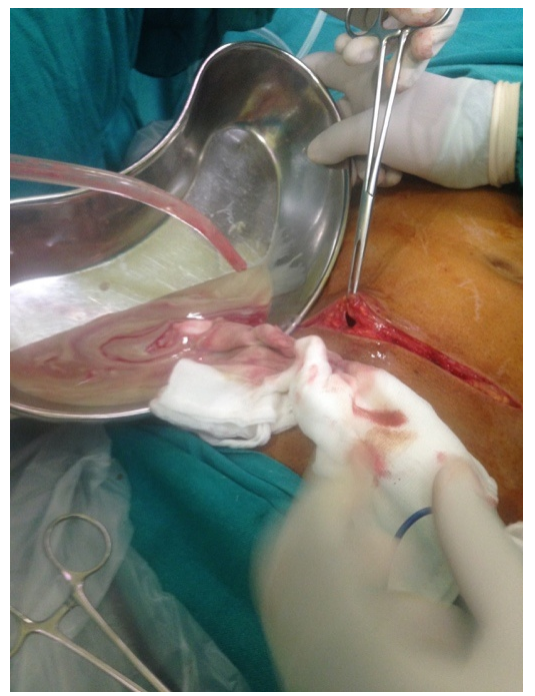

Figure 4. Large preperitoneal thick walled abscess cavity opened and $500 \mathrm{ml}$ of pus drained.

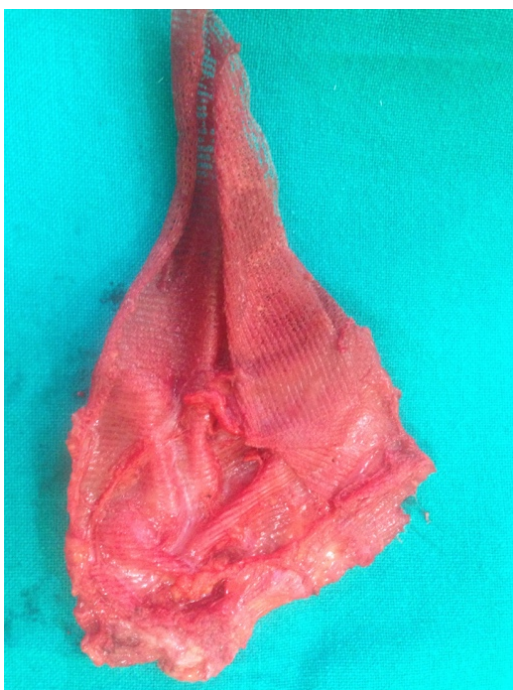

Figure 5. Explanted Polypropylene mesh.

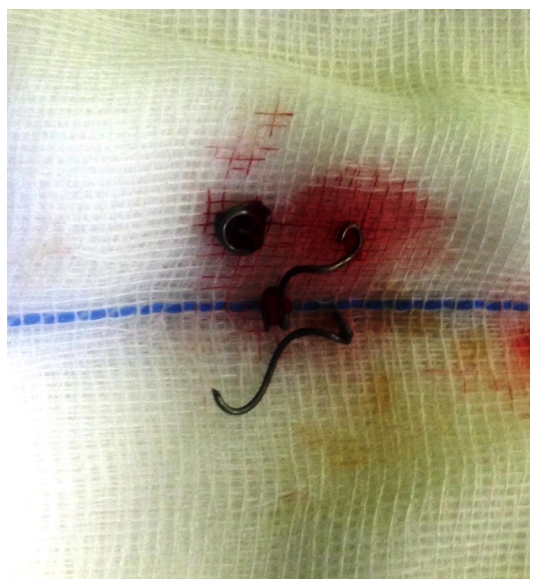

Figure 6. Extracted tacks, previously used to fix mesh in preperitoneal area. 


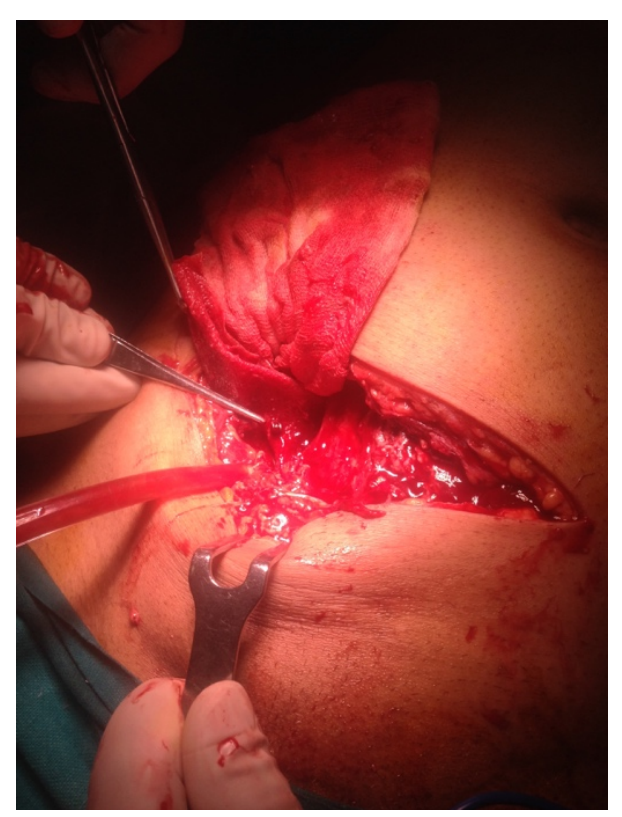

Figure 7. Cavity was explored and no communication was found inside peritoneal cavity.

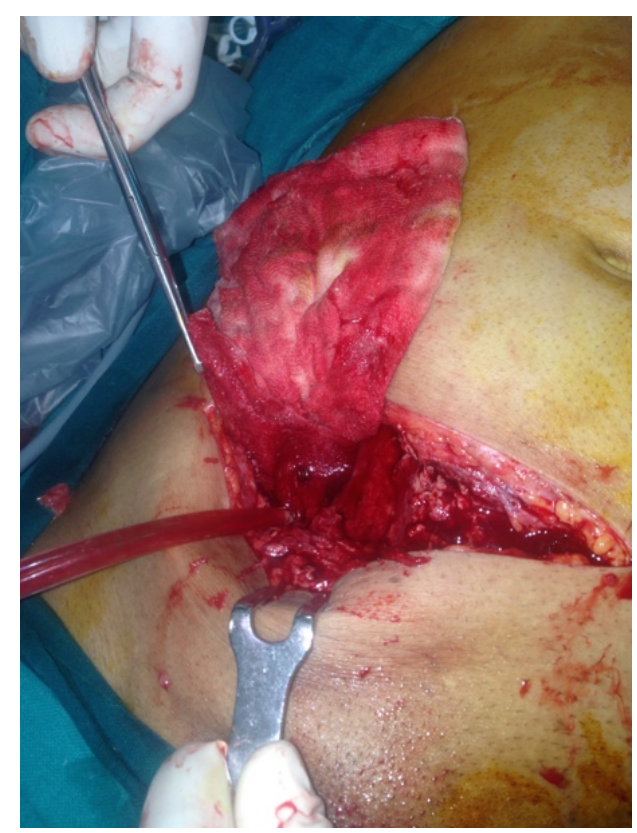

Figure 8. Lavage done and cavity closed with a drain inside.

\section{Follow-up}

After follow up for 1 year, patient continues to remain asymptomatic with no clinical evidence of recurrence of hernia or infection.

\section{Discussion}

The prosthetic material has the inherent danger of landing up in infection, both acute as well as delayed. Whereas the acute infections have mostly been due to a breach in 
sterilization process, the etiology and the true incidence of late onset mesh infection, however, remains to be established as only a few cases have been reported in the literature. Besides the sterilization breaks, different mesh characteristics like its type, filament pore size, type of suture material used have been implicated as potential contributory factors for infection [4] [5]. The incidence of fluid collection or seroma in the inguinal canal and around the mesh is common in laparoscopic hernia repair and in most cases requires no intervention. Patients with symptoms, however, may need aspiration. A high degree of caution is exercised to do it under strict aseptic conditions or else the patient might land up into infection and the consequences thereof, requiring removal of the mesh inevitable in infected cases [6] [7]. The long-term complications related to the mesh are reported to be rare with infection being one of the rarest ones [8]-[13]. Septic complications of the mesh have been reported to occur in $0.2 \%-0.8 \%$ of patients [14]. Gukas has reported a life-threatening complication 5 years after laparoscopic TEP hernia repair surgery [15]. There have been, however, isolated incidences when the extra-peritoneal mesh has become secondarily infected by the affliction of an intraperitoneal organ like a ruptured appendix or a perforated colonic diverticulum. Spiral tacks are extremely rare causes for mesh to become primarily infected or cause problems if it is used to close the peritoneum. They have also been reported to erode in adjacent viscera. Deep-seated infections involving mesh needs aggressive intervention including drainage of abscess and removal of mesh. Conservative surgical approaches such as abscess drainage, sinus excision or partial mesh excision can fail and result in recurrent mesh infections [16]-[18]. Removal of the infected mesh may not result in recurrent herniation if sufficient fibrous scarring remains. The initial reaction in response to surgically implanted prosthetic mesh is characterized by acute inflammatory cell infiltration followed by fibroblast infiltration through the interstices of the porous mesh, which gradually replace inflammatory cells [19]-[21]. A biologic mesh may be taken as a substitute for the infected mesh if the resulting defect is a concern.

Therefore, we conclude that in this era of increasing use of prosthetic materials (mesh), for any patient presenting with fever of unknown origin, or symptoms and/or signs of abdominal wall inflammation, we should consider late onset of a mesh-related infection as a differential diagnosis and should deal accordingly and efficiently.

\section{References}

[1] Schultz, C., Baca, I. and Götzen, V. (2001) Laparoscopic Inguinal Hernia Repair. Surgical Endoscopy, 15, 582-584. http://dx.doi.org/10.1007/s004640000376

[2] Kapiris, S.A., Brough, W.A., Royston, C.M., et al. (2001) Laparoscopic Transabdominal Preperitoneal (TAPP) Hernia Repair. A 7-Year Two-Center Experience in 3017 Patients. Surgical Endoscopy, 15, 972-975. http://dx.doi.org/10.1007/s004640080090

[3] Moon, V., Chaudry, G.A., Choy, C., et al. (2004) Mesh Infection in the Era of Laparoscopy. Journal of Laparoendoscopic \& Advanced Surgical Techniques and Videoscopy, 14, 349352. http://dx.doi.org/10.1089/lap.2004.14.349

[4] Deysine, M. (1998) Pathophysiology, Prevention, and Management of Prosthetic Infections in Hernia Surgery. Surgical Clinics of North America, 78, 1105-1115. 
http://dx.doi.org/10.1016/S0039-6109(05)70372-8

[5] Patti, J.M., Allen, B.L., McGavin, M.J., et al. (1994) MSCRAMM-Mediated Adherence of Microorganisms to Host Tissues. Annual Review of Microbiology, 48, 585-617. http://dx.doi.org/10.1146/annurev.mi.48.100194.003101

[6] Parra, J.A., Revuelta, S., Gallego, T., et al. (2004) Prosthetic Mesh Used for Inguinal and Ventral Hernia Repair: Normal Appearance and Complications in Ultrasound and CT. The British Journal of Radiology, 77, 261. http://dx.doi.org/10.1259/bjr/63333975

[7] Avtan, L., Avci, C., Bulut, T. and Fourtanier, G. (1997) Mesh Infections after Laparoscopic Inguinal Hernia Repair. Surgical Laparoscopy Endoscopy \& Percutaneous Techniques, 7, 192-195. http://dx.doi.org/10.1097/00019509-199706000-00002

[8] Hofbauer, C., Andersen, P.V., Juul, P. and Qvist, N. (1998) Late Mesh Rejection as a Complication to Transabdominal Preperitoneal Laparoscopic Hernia Repair. Surgical Endoscopy, 12, 1164-1165. http://dx.doi.org/10.1007/s004649900807

[9] Foschi, D., Corsi, F., Cellerino, P., Trabucchi, A. and Trabucchi, E. (1998) Late Rejection of the Mesh after Laparoscopic Hernia Repair. Surgical Endoscopy, 12, 455-457. http://dx.doi.org/10.1007/s004649900704

[10] Jalilvand, A., Sarker, S. and Fisichella, P.M. (2015) A Rare Case of Mesh Infection 3 Years after a Laparoscopic Totally Extraperitoneal (TEP) Inguinal Hernia Repair. Surgical Laparoscopy Endoscopy \& Percutaneous Techniques, 25, e69-e71. http://dx.doi.org/10.1097/SLE.0000000000000093

[11] Singh-Ranger, D., Taneja, T., Sroden, P., et al. (2007) A Rare Complication Following Laparoscopic TEP Repair: Case Report and Discussion of the Literature. Hernia, 11, 453-456. http://dx.doi.org/10.1007/s10029-007-0206-7

[12] Chowbey, P.K., Bagchi, N., Goel, A., et al. (2006) Mesh Migration into the Bladder after TEP Repair: A Rare Case Report. Surgical Laparoscopy Endoscopy \& Percutaneous Techniques, 16, 52-53. http://dx.doi.org/10.1097/01.sle.0000202185.34666.f1

[13] Bodenbach, M., Bschleipfer, T., Stoschek, M., Beckert, R. and Sparwasser, C. (2002) Intravesical Migration of a Polypropylene Mesh Implant 3 Years after Laparoscopic Transperitonealhernioplasty. Urologe A, 41, 366-368. http://dx.doi.org/10.1007/s00120-001-0148-0

[14] Furtschegger, A., Sandbichler, P., Judmaier, W., et al. (1995) Sonography in the Postoperative Evaluation of Laparoscopic Inguinal Hernia Repair. Journal of Ultrasound in Medicine, 14, 679-684.

[15] Gukas, I.D. and Massouh, F. (2011) Serious Life-Threatening Complication 5 Years after Laparoscopic Totally Extraperitoneal Hernia Repair: Case Report and Discussion of the Literature. Hernia, 15, 459-462. http://dx.doi.org/10.1007/s10029-010-0681-0

[16] Tolino, M.J., Tripoloni, D.E., Ratto, R. and Garcia, M.I. (2009) Infections Associated with Prosthetic Repairs of Abdominal Wall Hernias: Pathology, Management and Results. Hernia, 13, 631-637. http://dx.doi.org/10.1007/s10029-009-0541-y

[17] Berliner, S.D. (1993) Clinical Experience with an Inlay Expanded Polytetrafluoroethylene Soft Tissue Patch as an Adjunct in Inguinal Hernia Repair. Surgery, Gynecology \& Obstetrics, 176, 323-326.

[18] Marrie, T.J. and Costerton, J.W. (1984) Scanning and Transmission Electron Microscopy of in Situ Bacterial Colonization of Intravenous and Intraarterial Catheters. Journal of Clinical Microbiology, 19, 687-693.

[19] Arnaud, J.P., Eloy, R., Adloff, M. and Grenier, J.F. (1977) Critical Evaluation of Prosthetic Materials in Repair of Abdominal Wall Hernias: New Criteria of Tolerance and Resistance. The American Journal of Surgery, 133, 338-345. 
http://dx.doi.org/10.1016/0002-9610(77)90542-6

[20] Bellon, J.M., Bujan, J., Contreras, L., Hernando, A. and Jurado, F. (1994) Macrophage Response to Experimental Implantation of Polypropylene Prostheses. European Surgical Research, 26, 46-53. http://dx.doi.org/10.1159/000129317

[21] Tyrell, J., Silberman, H., Chandrasoma, P., Niland, J. and Shull, J. (1989) Absorbable versus Permanent Mesh in Abdominal Operations. Surgery, Gynecology \& Obstetrics, 168, 227232.

Submit or recommend next manuscript to SCIRP and we will provide best service for you:

Accepting pre-submission inquiries through Email, Facebook, LinkedIn, Twitter, etc. A wide selection of journals (inclusive of 9 subjects, more than 200 journals)

Providing 24-hour high-quality service

User-friendly online submission system

Fair and swift peer-review system

Efficient typesetting and proofreading procedure

Display of the result of downloads and visits, as well as the number of cited articles

Maximum dissemination of your research work

Submit your manuscript at: http://papersubmission.scirp.org/

Or contact ss@scirp.org 